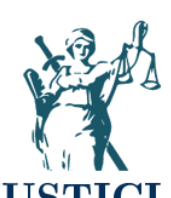

JUSTICIA

ISSN impreso 0124-744

\title{
Presencia diferenciada del Estado: El necropoder y las FARC Colombia
}

\section{Differential presence of the state: necro-power and FARC Colombia}

\author{
Alejandro Blanco Zuñiga \\ Universidad del Atlántico, Colombia \\ alejov84@hotmail.com \\ Jorge Arrieta Palis \\ Universidad del Atlántico, Colombia \\ jarrieta42@hotmail.com
}

Recibido: 27 de agosto de 2019 / Aceptado: 3 de noviembre de 2019

https://doi.org/10.17081/just.24.36.3518

\section{Resumen}

Tomando como referencia los diálogos de la Habana y frente a una posible superación de parte del conflicto armado con la insurgencia guerrillera, surge la necesidad de comprender las causas del surgimiento del ellas. En este trabajo se identifica a una de dichas causas, cuando se señalan los intentos de articulación del Estado con respecto a la zona de poblamiento de la resistencia armada donde aún no hacía presencia, a través de la necropolítica, entendida como el derecho soberano de matar. Para ello se colocarán los ejemplos de la guerra de Villarrica y la operación Marquetalia, puesto que estos ataques directos buscaban el exterminio de las colectividades que se hallaban en esas zonas donde el estado no ejercía soberanía, pues estas además de ser una simple expresión del poder del Estado soberano, tuvieron el efecto colateral de lograr que organización de resistencia armada se transformara.

Palabras Clave: Estado; FARC; Necropolítica; Soberanía; Conflicto Armado

\section{Abstract}

Facing a possible overcoming of part of the armed conflict with the insurgency guerrilla through the currents peace dialogues which are taking place in La Habana, to understand the reasons of the guerrilla's rise arouses as a need. One of them is identified, when are pointed the tryings of the articulation of the State respect the peopling zones of the armed resistance where there wasn't presence yet, by means of necro-politic, this concept is understood as the sovereign right to murder. Villarrica war and Marquetalia operation will be set as examples of that, knowing these direct attacks were intended to exterminate said collectivities, the organization of armed resistance transformed itself as a consequence of these simples expression of sovereignty.

Keywords: State; FARC; Necro-Politic; Sovereignty; Armed Conflict

\section{Como citar:}

Blanco Zuñiga , A., \& Arrieta Palis , J. (2019). Presencia diferenciada del Estado: El necropoder y las FARC Colombia . Justicia, 24(36), 58-69. https://doi.org/10.17081/just.24.36.3518

Justicia Vol. 24 No. 36: pp. 1-13. Julio - Diciembre, 2019. DOI: 10.17081/just.24.36

(C) Copyright 2019 by Blanco Zuñiga, A \& Arrienta Palis, J.

$$
\text { open (2)access (c) (1) }
$$




\section{INTRODUCCIÓN.}

Inicialmente se debe tener presente la necesidad innegable hacia la comprensión de las causas que dieron origen al conflicto como parte fundamental para la superación de este, por esto y en aras de entregar una contribución -aunque mínima- con vista a la transformación de nuestra Colombia se ha desarrollado este artículo, y más particularmente en lo que se refiere al surgimiento del conflicto con las Fuerzas Armadas Revolucionarias de Colombia, inspirados en la coyuntura de los diálogos de La Habana.

La cuestión del origen de las FARC, ha representado durante mucho tiempo el motivo de muchas indagaciones, tanto desde sus dinámicas internas, como de las injerencias externas a esta colectividad, ya sea por influencias de elementos a nivel nacional (otras organizaciones, el gobierno nacional, etc.) o desde los escenarios a nivel internacional (distintas revoluciones, las políticas imperialistas norteamericanas), poder esclarecer donde se encontraron las causas que pudieron determinar que surgiera dicha insurgencia.

Por ello se plantea como objetivo, exponer una tipología sobre el Estado Colombiano, para luego colocarlo en relación a ciertas expresiones de soberanía que pudieron ocasionar mutaciones dentro del movimiento, aras de presentar una aproximación causal mínima de una de las causas que determinaron el nacimiento de las FARC como insurgencia guerrillera.

Pero lo anterior implica hacer dos advertencias previas sobre la manera en que se ha querido plantear esta investigación, teniendo en cuenta las limitaciones que impone la magnitud del tema estudiado. Una primera advertencia, que se considera primordial es la esbozada por el Maestro Sergio de Zubiría, que señala:

“(...) sobre el conflicto, existe un consenso que nutre el debate histórico: sus facetas son múltiples, esto es, no es posible una explicación unicausal o monocausal, pues existen elementos estructurales que remiten a la totalidad de la estructura social colombiana. Las divergencias comienzan con los enfoques teóricos, los orígenes (...)”. (DE ZUBIRIA, 2015)

Hay que seguir este enunciado, para señalar que la diversificación de la teoría en torno a la explicación conflicto es un consenso en Colombia, partiendo del hecho de que este mismo tiene una causalidad múltiple, y por lo tanto puede existir más de una forma de abordarlo y de describirlo.

En segunda medida se debe señalar que no hace parte de nuestra empresa describir de forma completa el conflicto, puesto que sería demasiado extenuante y de sobremanera ambicioso, por lo tanto bastará con situar nuestro trabajo en:

“(...) conexiones parciales entre posiciones materiales y semióticas (en el que intervienen actores - y actantes - humanos, tecnológicos, "naturales", híbridos...). Estos conocimientos son parciales ya que surgen a partir de las circunstancias semióticomateriales de las posiciones y articulaciones particulares que 
están en continua transformación." (MONTENEGRO \& PUJOL, 2003)

\section{METODOLOGIA}

Por lo anterior y para efectos de esta investigación, se analizará en primera medida las teorías que de manera preponderante han descrito el Estado Colombiano, para entender la necesidad de articulación de las regiones periféricas al poder central, puesto que esto tiene una doble implicación; primero porque es fundamental para hacer una teorización que coloque al Estado con respecto a la forma en que se presenta en relación al territorio en el marco del ejercicio soberano, y por otro lado comprender a la violencia como ejercicio último de la soberanía del Estado.

Lo anterior tendrá la finalidad de construir insumos para comprender dos eventos sumamente importantes en el surgimiento de la guerrilla de las FARC, como lo son la guerra a Villarrica y el ataque denominado "Operación Marquetalia", pues permiten ver de dónde proceden las mutaciones definitivas de este grupo.

Dado lo anterior, se desprende que comprender el conflicto armado colombiano en todas sus dimensiones resulta una labor compleja, por cuanto el abordaje de este problema implica una serie de posibilidades a través de distintos entornos científicos, por lo que es pertinente entonces, resaltar que parte de la complejidad reside en la idea de advertir que el conflicto por su misma naturaleza no es homogéneo, ello quiere decir que las guerra en Colombia es asimétrica y que tiene matices, y estos están determinados por el ámbito regional, la guerra por sus propias características no se manifestó con la misma intensidad en distintas regiones del país.

\section{RESULTADOS}

\section{a) El debate en torno a una teoría del estado colombiano}

Trabajar la conceptualización del Estado Colombiano es una tarea que se presenta compleja, pues no pocas han sido las teorías sobre este, y muchas de ellas están aún en discusión o por ser replanteadas, no obstante, seguiremos el hilo conductor de algunas de la más representativas de ellas, particularmente tres; Estado fallido, precariedad del Estado, colapso parcial del Estado, y por último la presencia diferenciada del Estado en especio y tiempo.

Hay que decir primeramente que el concepto de Estado fallido, es un concepto explorado a partir del estudio de diversos países que pertenecen al continente africano y que produjeron una serie de índices, que fueron desarrollados con base en sugerencias de instituciones internacionales como el Banco Mundial (BM) y el Programa de las Naciones Unidas para el Desarrollo (PNUD), en aras de que los países que se encuentra en "estado crítico" tengan estabilidad para la "gobernabilidad", analizándolos comparativamente con los modelos democráticos de países "desarrollados" de América del Norte y Europa.

Estos, como lo señala Robert Rottberg (2010) tienen como índice final la perdida de legitimidad de los Estados frente a los ciudadanos, no obstante este viene acompañado de dinámicas, tales como: existencia de violencia interna, falta de autoridad para la toma de decisiones por parte del poder ejecutivo, politización de la fuerza pública, incapacidad de prestar servicios públicos básicos, altos índices de desigualdad, corrupción generalizada, entre otros, esto hace que las lealtades de la población se transfieran a bandas de criminales o señores de la guerra, esto último sería como una especie de transferencia de la legitimidad.

Y de hecho el estudio en torno al concepto de Estado fallido, están encaminados a la construcción de gobernabilidad dentro de los países que no han alcanzado los estándares de los países "ejemplares", pues este diagnóstico está encaminado tal como lo señala Robert Rottberg 
(2010) de lo que se trata es de revivir, reparar y reconstruir países, para hacerlos gobernables y con democracias sostenibles.

Sin embargo, la categoría tiene una seria falencia, que la deshace, teniendo en cuanta que es necesario reconocer que la aspiración de país solido que propone como generalidad este índice, para la gran mayoría de naciones a nivel mundial es apenas una quimera, y presentar el modelo de Estado-Nación europeo o norteamericano como ejemplo a seguir, sería desconocer la historia y las particularidades de los países evaluados (MANN, 1999).

Por otra parte encontramos el concepto de precariedad del Estado que es desarrollado por el francés Daniel Pécaut (2001), que pone de manifiesto una característica central de la política en Colombia, que es precisamente ser precaria, puesto que aparece en ella no solo el típico rasgo de inexistencia de instituciones estatales en el territorio, sino también la incapacidad del Estado de regular la vida en sociedad.

Lo anterior produjo un sistema donde: la violencia es consustancial al ejercicio de una democracia que, en lugar de tomar como referencia la homogeneidad de los ciudadanos, descansa sobre la conservación de sus diferencias "naturales", sobre adhesiones colectivas y las redes privadas de dominación social; y que no aspira a institucionalizar las relaciones de fuerza que irrigan la sociedad, ya que hace de ellas un resorte de su continuidad (Pécaut, 2001).

En últimas y siguiendo al francés Pécaut (2001) explica que el fenómeno político Colombiano de lucha entre elites dominantes (redes privadas de dominación) por un lado y la subordinación de las clases populares por otro, restringió la posibilidad de dictaduras fuertes y populismos de corte personalista, toda vez que los partidos políticos de dichas elites dispersaron el poder dentro de esta pequeña franja, que competía ente sí, y en muchos casos suplieron el papel del mismo Estado, al garantizar cierta estabilidad económica y política.

En síntesis importancia de la precariedad del Estado es que esta es una propuesta que mira el Estado en relación a su contexto, describiendo las dinámicas propias de Colombia, esto será retomado más adelante retomaremos para un momento de superación de teorías.

Tenemos también un concepto denominado colapso parcial del Estado el cual es desarrollado para poner de relieve: "la crisis de inoperancia de las instituciones establecidas, la perdida de legitimidad del Estado, la apelación del mismo a prácticas terroristas que debilitaron aún más la estructuras sociales existentes, la ausencia física del estado en grandes regiones del país y las contradicciones dentro del aparato armado del mismo" (OQUIST, 1978).

Siguiendo a Paul Oquist (1978) se puede decir que este colapso parcial del Estado tiene una estrecha importancia dentro del plano central del territorio, puesto que para las zonas más apartadas las donde el Estado no existía, los conflictos se resolvían sin recurrir a la autoridad, teniendo en cuenta que los poderes regionales y locales regulaban la vida social, no se generara caos dentro de dichos territorios pese a la "ruptura" con las estructuras del centro.

Lo anterior conlleva a una importante reflexión: "la ausencia del Estado, por sí sola, no conduce violencia si no coincide con el deterioro de otras formas de control social y con el surgimiento de contradicciones sociales que no pueden resolverse apelando a los mecanismos tradicionales" (OQUIST, 1978).

Esto último pone en la mesa una deducción importante, y es que precisamente la ausencia del Estado, no significa ni inexistencia de poder, ni existencia de violencia, dentro de las regiones o localidades donde el poder central no hace presencia física, sin embargo esta exposición es aún precaria, pues aunque manifiesta la existencia de poderes "de facto" -si se permite llamarles asídiferentes del poder central, no obstante nunca menciona la necesidad de poner el Estado en contexto, y esta propuesta nace de un tipo ideal de Estado.

Es en este punto donde nace la propuesta de presencia diferenciada del Estado en el espacio y tiempo, que el retoma debate de la formación del Estado partiendo de tres exposición, primero desde Mary Roldan (2002) pues ella pone en la mesa la necesaria discusión sobre el carácter que 
asume el poder del Estado en las regiones donde no hace presencia, teniendo en cuenta la necesidad de articulación de dichas regiones o localidades. Así pues y en cuanto a los lugares aun donde el Estado aun no hace presencia y parafraseando a Roldan (2002), los territorios integrados al centro la violencia es canalizada por los partidos políticos y sus mecanismos burocráticos, mientras que en los territorios periféricos de colonización, donde se presentan conflictos de tipo económico-sociales el Estado entra directamente con el ejército.

Segundo la conceptualización de María Teresa Uribe (2001) cuando propone el concepto de estados de guerra, donde no solo hay una caracterización que va más allá, pues habla de aquellos lugares donde el Estado no solo no hace presencia, sino que además se opone a su ingreso, incluso con las armas, representado un límite a la misma soberanía estatal y al monopolio del uso de la fuerza.

Y tercero, retoma el planteamiento contextual de Pécaut, el ya mencionado anteriormente análisis contextual del Estado Colombiano, para finalmente obtener la idea de “(...) un Estado en formación, (...) que tiene que ver con el poblamiento del territorio, la organización de la cohesión social interna de sus poblaciones y la articulación de ellas al Estado nacional de Colombia" (GONZÁLEZ, 2015). Con esto se abre el campo a la aplicación de una perspectiva diferente, sino que recrea la forma en que nuestro Estado llega a las poblaciones y las va articulando al centro.

Dicha tesis también se encarga de precisar a Colombia como Estado, que considera a nuestro país en vez de "Estado fallido, que ha perdido el monopolio de la coerción se trataría de un Estado que va integrando gradualmente nuevos territorios y poblaciones marginales, donde la presencia de las instituciones estatales no es homogénea sino desigual de acuerdo con el grado de articulación de esas regiones con el centro del país y según el tipo de región que se establece entre el Estado central y los poderes de hecho existentes en regiones y localidades" (GONZÁLEZ, 2015).

Precisamente lo anterior nos permite tener en cuenta que el Estado central se va relacionan con los poderes "de facto" preexistentes dentro del territorio nacional, pero esa relación de articulación se presenta de diferentes maneras, dependiendo de territorio y del poder "de facto" o prexistente. Es importante en este momento de la exposición tener presente que: "Una será la violencia que confronta el dominio directo del Estado, muy distinta de la que se desarrolla donde este dominio del Estado debe ser negociado y articulado con las estructuras de poder, y otra, muy diferente, es la violencia que se produce donde no se han logrado consolidar los mecanismos tradicionales de regulación social, o donde estos mecanismos están haciendo crisis." (GONZÁLEZ, 2003)

En resumen, esta perspectiva que ofrece la propuesta de presencia diferenciada del Estado en espacio y tiempo, muestra la existencia de una articulación diferenciada en Colombia, a través de la cual analizaremos el discurso de la soberanía como mecanismo legitimador de una de las formas de articulación; la que se ejerce de manera violencia desde el Estado hacia zonas donde aún no se ha logado consolidar mecanismos tradicionales de regulación social, para así finalmente tener insumos suficientes que nos permitan dar una explicación a lo ocurrido en Marquetalia, e inmediatamente el nacimiento de la guerrilla de las FARC.

\section{b) El necropoder como expresión última de la soberanía}

Pero hablar de la soberanía en los términos en que se quiere plantear, esta exposición se distanciara de la concepción tradicional de soberanía que expone las ciencias politicas, que sugiere a un poder ubicado sobre las instituciones nacionales y supranacionales situadas bajo el orden de la autoridad estatal.

En vez de la idea anterior, esta exploración de la soberanía parte del criterio expuesto por el pensador francés Michel Foucault, y su idea de biopolítica, la cual vendría siendo "El conjunto de mecanismos por medio de los cuales aquello que, en la especie humana, constituye sus rasgos biológicos fundamentales podrá ser parte de una política, una estrategia política, una estrategia general de poder" (FOUCAULT, 2006). 
Precisamente estrategia de poder, que el mismo Foucault llama biopoder, buscara mediante la implantación de discursos (o dispositivos de poder) dentro de las diferentes esferas de la cotidianidad, tal como lo señala el francés: "se trata de un conjunto de procesos como la proporción de los nacimientos y las defunciones, la tasa de reproducción, la fecundidad de una población, etc. Estos procesos de natalidad, mortalidad y longevidad constituyeron, a mi entender, justamente en la segunda mitad del siglo XVIII y en conexión con toda una masa de problemas económicos y políticos (a los que no me voy a referir ahora), los primeros objetos de saber y los primeros blancos de control de esa biopolítica."(FOUCAULT, 2001)

Pero finalmente ese poder sobre lo biológico termina sugiriendo una metamorfosis de la soberanía, pues para Foucault (2001) "el poder de la soberanía, y que consistía en poder hacer morir, he aquí que, con la tecnología del biopoder, la tecnología del poder sobre la población como tal, sobre el hombre como ser viviente, aparece ahora un poder continuo, sabio, que es el poder de hacer vivir. La soberanía hacía morir y dejaba vivir. Y resulta que ahora aparece un poder que yo llamaría de regularización y que consiste, al contrario, en hacer vivir y dejar morir."

Pero la anterior cuestión se traduce una objeción, que se incita con ocasión de este trabajo: “¿La noción de biopoder acaso da cuenta de la forma en que la política hace hoy del asesinato de su enemigo su objetivo primero y absoluto, con el pretexto de la guerra, de la resistencia o de la lucha contra el terror?" (MBEMBE, 2011), es aquí donde se inserta la percepción que atribuimos a la expresión de la soberanía, más como una decisión de "quién puede vivir y quién debe morir" (MBEMBE, 2011), que como un hacer vivir como lo plantea Foucault.

Pero más a profundidad, es en este replanteamiento del concepto de biopolítica de Foucault en relación al ejercicio del biopoder, es donde aparece la idea de necropolítica, que será plateada por Achille Mbembe, a su vez su ejercicio es el uso de la violencia como herramienta de exterminio, a la cual llamará necropoder.

El necropoder tiene como su sustento conceptual dos importantes pilares: "el estado de excepción y la relación de enemistad se han convenido en la base normativa del derecho de matar. En estas situaciones, el poder (que no es necesariamente un poder estatal) hace referencia continua e invoca la excepción, la urgencia y una noción «ficcionalizada» del enemigo."(MBEMBE, 2011).

En concordancia con la anterior la puesta en marcha del necropoder solo es posible a través de la construcción de un "enemigo" a eliminar, y con el impulso del "estado de excepción", dicho "enemigo" es el producto de una noción ficticia (racismo, ideología, etc.), que funge como legitimadora del ejercicio de este poder.

En ultimas y para dejar en claro la noción de necropoder, es importante añadir que esta es el ejercicio del poder de Estado, y es un fenómeno que se produce bajo la perspectiva de la soberanía como "el derecho de matar", asentando en "La percepción de la existencia del Otro como un atentado a mi propia vida, como una amenaza mortal o un peligro absoluto cuya eliminación biofísica reforzaría mi potencial de vida y de seguridad (...)" (MBEMBE, 2011).

\section{c) El ejercicio articulador del estado y el necropoder como orgien de las farc: la guerra a villarrica y la "operación marquetalia"}

En esta última parte, se mostrará como la puesta en escena del necropoder, como ejercicio de la soberanía del Estado en su intención de articular la región donde se asentaron las autodefensas campesinas, tanto durante la dictadura de Rojas Pinilla con la guerra a Villarrica, como en el Frente Nacional durante el gobierno de Guillermo León Valencia con la operación Marquetalia, generaron mutaciones importantes a las colectividades asentadas en esta región que a la postre terminaron por precipitar el nacimiento de las FARC, sin dejar de lado que durante este tiempo hubo un remarcado uso del Estado de excepción y la existencia de un discurso que sugería un enemigo; El comunismo. 
Antes de pormenorizar dos importantes hitos que modificaron a profundidad la forma de organizacional de las FARC, es necesario señalar que las zonas donde se ubicó esta resistencia armada, antes de convertirse en el grupo insurgente que conocemos hoy, siempre pobló regiones aun no articuladas por el Estado, donde aún no hacia presencia, zonas como Villarrica y Marquetalia aparecerían en el tiempo y espacio de Colombia debido a que estos grupos los incluyeron allí, en palabras más precisas "Espacios y territorios de construyen y reconstruyen en la dinámica misma de la resistencia, en donde surgen caseríos y zonas de colonización que evolucionan (...)" (MEDINA, 2010).

En dichas zonas de colonización y de expansión territorial, es donde se movió la resistencia campesina armada, durante los periodos de Rojas Pinilla y Guillermo León Valencia, y precisamente serían las zonas que intentarían articular el Estado dentro de su poder soberano, y con el uso del necropoder.

\section{d) La dictadura de gustavo rojas pinilla y la guerra contra villarrica}

La embestida contra la resistencia armada durante la dictadura de Gustavo Rojas Pinilla en se presentaría como ya se señaló, en el marco de un discurso anticomunista, tal como se reseña a continuación:

(...) la promulgación del Acto Legislativo Número 6 de 1954 de la Asamblea Nacional Constituyente, que manipulaba la dictadura de Rojas Pinilla, por el cual se declaró por fuera de la ley al comunismo con lo que se abrió un oscuro periodo de persecución, no solo a este partido sino a miles de ciudadanos de todos los sectores; como dijera Gilberto Vieira en una carta abierta a dicha

Asamblea, "la ilegalización es un problema que no atañe únicamente a los comunistas sino también a todos los demócratas y patriotas colombianos, porque con esa medida se crea un arma de persecución ideológica y se establece el delito" (ROMERO, 2014)

Luego que este ofreciera una amnistía general para apaciguar el periodo de "la Violencia", dicho discurso anti-comunista tuvo importantes repercusiones, y precisamente producto de este se presenta la guerra de Villarrica. En esta zona del país en donde había un asentamiento significativo de campesinos influenciados por el partido comunista, que trataban de labrar el campo y que para ese momento, dicho movimiento era comandado por Juan de la Cruz Varela, dicha guerra es reseñada por Alfredo Molano, así:

"La embajada norteamericana informó a su gobierno que entre el 7 y el 10 de junio Villarrica había sido destruida por el

bombardeo aéreo y por el incendio causado por las bombas napalm. La Fuerza Aérea "nos informó privadamente que la FAC arrojó aproximadamente 50 bombas napalm fabricadas aquí (en Colombia)", lo que permitió la captura de la Colonia, que habia sido zona de colonización desde los años 40 y que el Ejército 
consideraba la sede del movimiento comunista." (MOLANO, 2004).

Villarrica es testimonio de la idea de articulación del Estado, de zonas colonizadas por el movimiento comunista, a través del ejercicio del necropoder, que bajo el discurso anti-comunista legitimó, el exterminio de quienes poblaban esa zona, es decir, la soberanía del Estado en este evento decidió matar, y no dejar vivir. Este ataque a su vez traería una transformación a este movimiento:

Precisamente de este momento de persecución y asedio comprendido entre 1954 y 1958 por parte del gobierno de Rojas Pinilla, y que tuvo como climax la guerra de Villarrica se produjo una mutación en el movimiento, pues este se transforma en una especie de guerrilla móvil, puesto el PCC "ordenó a los grupos de autodefensa asentados en Tierradentro y el sur del Tolima reactivarse como guerrilla móvil, lo cual realizaron bajo la conducción de Ciro Trujillo y Manuel Marulanda, respectivamente. Con lo cual se dio origen a la "segunda etapa de la guerrilla", caracterizada por el predominio de los núcleos comunistas."(PIZARRO, 1989).

\section{e) Operación marquetalia y el mito fundacional de las farc}

Así mismo y fruto de la aparición en la escena política del Frente Nacional, y habiendo ya mermado las persecuciones de parte del gobierno de Pinilla, la resistencia armada se transforma nuevamente en autodefensas campesinas, las cuales eran asentamiento donde los grupos guerrilleros comunistas se organizaban con una estructura social y militar, las zonas donde se ubicarían serían El Pato, Rio Chiquito, Guayabero y Marquetalia.

Estas nuevos asentamientos con estructura político-militar en las regiones anteriormente mencionadas serán vistos con recelo desde el Estado, en especial por el congresista Álvaro Gómez (hijo del expresidente Laureano Gómez), cual les denominaría las "repúblicas independientes", y también las señalaría como partes de territorio dominadas por el "enemigo interno" (VÉLEZ, 2001), este discurso seguía las directrices del proyecto "anticomunista" y contrainsurgente que pondría en marcha el Frente Nacional, y que tendría su epicentro durante el mandato León Valencia, pues:

"la fase culminante de una gran campaña lanzada por el gobierno de Guillermo León Valencia en enero de 1964 con el propósito de eliminar los grupos de bandoleros en que habian terminado convertidas las guerrillas liberales del norte del Tolima, mantener el control sobre la zona central del departamento y 'adelantar operaciones encaminadas a producir el aislamiento efectivo de los núcleos comunistas en armas en el sur'." (REVISTA SEMANA, 1999)

Todo este grupo de cosas logró que se iniciara una avanzada militar por parte del Estado, que sería denominada la "Operación Marquetalia", esta constó en:

"El 27 de mayo de 1994 se inició la operación militar contra Marquetalia con un importante contingente bajo el mando del coronel Hernando Correa Cubides, comandante de la VI Brigada, 
con sede en Ibagué. Este dispuso de la totalidad de los helicópteros con que contaban en ese entonces las Fuerzas Armadas, de compañias del Ejército especializadas en la lucha de contrainsurgencia, de grupos de inteligencia y localización (GIL) formados en la Escuela de Lanceros de Tolemaida y, finalmente, de aviones de combate T-33. Un descomunal esfuerzo militar."

(PIZARRO, 2004).

Este ataque de parte del Frente Nacional se produce con la idea de eliminar esas soberanías alternas ("las repúblicas independientes") y articularlas al Estado, otra vez bajo el ejercicio del necropoder, pero esto aunque produjo una parcial recuperación del control sobre este territorio, también representaría dos cosas para los asentamientos comunistas.

De una parte supondría una victoria para los subversivos, puesto que no tuvieron considerables bajas y soportaron el arrecio del Estado, y de hecho este evento de resistencia sería luego considerado por las FARC como el "mito fundacional" y símbolo para esta organización.

Y por otra parte: "El resultado fue que a partir de esta agresión la autodefensa se transformó en movimiento guerrillero. Y la lucha armada de inspiración comunista se extendió hacia otras zonas, con la creación de los destacamentos guerrilleros de Guayabero, El Pato, Chaparral, Natagaima, Riochiquito y naturalmente, el de Marquetalia (...) Sin duda, la invasión militar a Marquetalia se constituirá en un enorme error histórico de parte de la clase dirigente colombiana." (PIZARRO, 1989)

\section{CONCLUSIONES}

Para concluir, el análisis realizado con anterioridad arroja importantes conclusiones a la hora de establecer como una de las causas del conflicto en el acápite especifico de la construcción del Estado Colombiano partiendo de un estudio tipológico de este, llegando a la propuesta de presencia diferenciada del Estado en tiempo y espacio, la cual permite comprender que el Estado Colombiano ha ido articulando el territorio poco a poco, a través de diferentes formas, dependiendo de las condiciones para de dicho lugar.

Ahora bien, resulta pertinente resaltar que es complicado para las ciencias sociales, si se tiene en cuenta la enorme complejidad de la guerra en Colombia, establecer la génesis histórica de la guerra en Colombia, dadas teniendo en cuenta los diversos matices que se presentaron en ella y la prolongación que ha tenido, así como también las circunstancias sobres las que cabalgan los fenómenos sociales que permitieron el surgimiento de la confrontación armada.

En ese punto articulador diferenciado es donde aparece la necropolítica como ejercicio del poder soberano del Estado sobre el derecho de matar, que sería ejercido en un plano más concreto contra los grupos establecidos en zonas donde el Estado no tenía el control directo, y donde no podía imponerlo mediante mecanismos tradicionales, como lo demuestran los casos de la guerra de Villarrica y la Operación Marquetalia.

En ultimas la violencia ejercida tanto en Villarrica y como en la Operación Marquetalia, producen una incidencia directa dentro de las colectividades semilla de lo que es hoy el grupo guerrillero comunista de las FARC, esto explica una parte de su transformación, a partir de la injerencia del poder soberano del Estado directamente contra dichas regiones, en aras de controlarlas.

\section{REFERENCIAS}


De Zubiria, S. (6 de Julio de 2015). Dimensiones políticas y culturales en el conflicto armado Colombiano. Obtenido de Centro de Memoria Historica: http://www.centrodememoriahistorica.gov.co/descargas/comisionPaz2015/zubiriaSergio.pdf

Foucault, M. (2001). Defender la sociedad. Buenos Aires: FCE.

Foucault, M. (2006). Seguridad, territorio y población. Buenos Aires: FCE.

González, F. (2003). ¿Colapso parcial o presencia diferenciada del estado en Colombia?: una mirada desde la historia. Colombia Internacional, 124-158

González, F. (2015). Poder y violencia en Colombia. Bogotá: Cinep.

Mann, M. (1999). El futuro global de los Estados-Nación. Revista análisis político.

Mbembe, A. (2011). Necropolitica. Madrid: Melusina.

Medina, C. (2010). FARC-EP: Notas para una historia política 1958-2008. Bogotá: Universidad Nacional.

Molano, A. (7 de Junio de 2014). Nacimiento de las Farc: De El Davis a Villarrica. Obtenido de El Espectador: http://www.elespectador.com/noticias/nacional/nacimiento-de-farc-de-el-davisvillarrica-articulo-497036

Montenegro, M., \& PUJOL, T. (2003). Conocimiento situado: un forcejeo entre el relativismo construccionista y la necesidad de fundamentar la acción. Revista interamericana de psicología, 296-303.

Oquist, P. (1978). Violencia, política y conflicto en Colombia. Bogotá: Instituto de Estudios Colombianos, Biblioteca del Banco Popular.

Pécaut, D. (2012). Orden y violencia: Colombia 1930-1953. Medellín: Fondo Editorial Universidad EAFIT.

Pizarro, E. (1989). Los orígenes del Movimiento armado Comunista en Colombia (1949-1966). Revista Análisis político.

Pizarro, E. (9 de mayo de 2004) Marquetalia: el mito fundacional de las Farc. 2006 Obtenido de Periódico Universidad Nacional: http://webcache.googleusercontent.com/search?q=cache:cMGGWUqBBzUJ:historico.unperi odico.unal.edu.co/ediciones/57/03.htm $+\& \mathrm{~cd}=1 \& \mathrm{hl}=\mathrm{es} \& \mathrm{ct}=\mathrm{clnk} \& \mathrm{gl}=\mathrm{co}$

Revista Semana. (28 de Junio de 1999). Marquetalia 35 años después. Obtenido de Revista Semana: http://www.semana.com/especiales/articulo/marquetalia-35-aos-despues/39734-3

Roldan, M. (2002). A sangre y fuego: La violencia en Antioquia, Colombia, 1946-1953. Bogotá: Icanh, Fundación para la promoción de la Ciencia y la tecnología.

Romero, R.(15 de septiembre de 2014) Victimización y anticomunismo: Cuando Rojas Pinilla ilegalizó al Partido Comunista. Obtenido de PACOCOL: http://www.pacocol.org/index.php/noticias/11035-victimizacion-y-anticomunismo-cuandorojas-pinilla-ilegalizo-al-partido-comunista

Rottberg, R. (2004). The failure and collapse of Nation-States: Breakdown, prevention, and repair. En R. Rottberg, When States fail: causes and consequences (págs. 1-51). New Jersey: Pricenton University Press. 
Uribe, M.T. (2001). Las soberanías en disputa: ¿conflicto de identidades o de derechos?, en M.T. Uribe. Nación, ciudadano y soberano. Medellín: Corporación Región.

Vélez, M. (2001). FARC-ELN: Evolución y expansión territorial. Revista Desarrollo y Sociedad, 151225. 